\title{
Green synthesis of silver nanoparticles using Morus nigra leave extract and evaluation their antifungal potency on phytopathogenic fungi
}

\author{
Rania A. Hafez ${ }^{1}$, Mosaad A. Abdel-Wahhab ${ }^{2 *}$, Ahmed F. Sehab ${ }^{3}$, Al-Zahraa A. Karam El-Din ${ }^{1}$ \\ ${ }^{1}$ Microbiology Dept., Faculty of Science, Ain Shams University, Cairo, Egypt. \\ ${ }^{2}$ Food Toxicology \& Contaminants Dept., National Research Center, Dokki, Cairo, Egypt. \\ ${ }^{3}$ Plant Pathology Dept., National Research Center, Dokki, Cairo, Egypt.
}

\section{ARTICLE INFO}

Article history:

Received on: 29/10/2016

Accepted on: 24/11/2016

Available online: 27/02/2017

Key words:

Morus nigra, antifungal

potential, nanosilver,

antimycotoxin activity,

aflatoxins.

\begin{abstract}
This study aimed to isolate and identify the fungi associated with white and yellow corn grain and peanuts seeds samples collected from different distracts at Cairo, to use Morus nigra leaves extract for the green synthesis of silver nanoparticles (AgNPs) and to evaluate the antifungal potency and anti-aflatoxin production of the synthesized AgNPs. White and yellow corn and peanut seeds samples were collected from 4 different districts of Cairo, mycoflora were isolated on Potato dextrose agar (PDA), Nash and Coon's media. The results revealed the isolation of sixteen fungal species belonging to 7 genera were recovered and identified during this study. The produced AgNPs showed Uv/Vis absorbance at $425 \mathrm{~nm}$ and particles sizes ranged from 4 to $8 \mathrm{~nm}$. Both AgNPs and the plant extract showed a strong antifungal activity against $P$. carryophylum; $F$. verticillioides; $A$. flavus; $A$. terreus and $F$. oxysporum using different techniques. Moreover, AgNPs was more effective than the plant extract against the tested fungi and anti-aflatoxin production by A. parasiticus. It could be concluded that the Morus nigra leaves extract can be used for the syntheses of AgNPs and also as antifungal of plant disease. Thus, Morus nigra and AgNPs could be used as effective, safe and ecofriendly antifungals to prevent fungal growth and subsequent aflatoxins production.
\end{abstract}

\section{INTRODUCTION}

Seed-borne fungi have been found to affect the growth and productivity of crop plants including legumes and cereals (Weber et al., 2001), in addition some species can produce health-damaging mycotoxins. The mycotoxins contamination in animal feed and human food represent a serious health and economic problem worldwide. Mycotoxins are secondary metabolites of several species of fungi. They are unavoidable and their production is depending on the environmental factors either in the field or during storage (Stoev, 2013). The majority of mycotoxins are potentially carcinogenic, tremorogenic, teratogenic, immunotoxic, nephrotoxic or hemorrhagic beside most of them cause dermatitis in both livestock and humans (Bhat and Reddy, 2017).

* Corresponding Author

E-mail: mosaad_abdelwahhab @yahoo.com

Tel.: +2 2283 1943; fax: +233370931
Among all mycotoxins, aflatoxin $\mathrm{B}_{1}\left(\mathrm{AFB}_{1}\right)$ is known to be the most significant in terms of animal and human health risk (CAST, 2003; Bryden, 2012). The control of phytopathogenic fungi is the first step towards the protection of cereal crop programs. Though successful, however, synthetic fungicides have main disadvantages such as; the accumulation in the ecosystem and the development of pesticide resistance pathogens (Okigbo, 2004).

Plants produce enormous array of secondary metabolites which serves to protect them against different pathogens. Mulberry (Morus nigra, Family: Moraceae) leaves have been used for the treatment of inflammation, hyperglycemia, cough, and fever (Radojković et al., 2016) due to its high content of phenolics with strong antioxidant activities which are thought to contribute to the biological activities of these leaves (Naowaratwattana et al., 2010). A problem with the use of plant-produced compounds as potential fungicides, is that in their natural state they are generally weakly active compared to synthetic fungicides (Gisi, 2014). 
Recently, metal nanoparticles have acquired a great attention because of their noteworthy properties, which are largely different than the original metals (Li et al., 2015; Xu et al., 2013).

Silver nanoparticles (AgNPs) have a great recognition due to several superior properties and their widely application in various fields (Yan et al., 2014; Nemanashi and Meijboom, 2013). However, the applications are dependent mainly on their size, shape, sizes distribution and stability of AgNPs in aqueous solution (Abdel-Aziz et al., 2014). Several strategies chemical and physical methods were developed for the synthesis of AgNPs included chemical reduction, radiation, microwave-assisted synthesis, ultrasonic irradiation, photo reduction, electrochemical reduction and chemical reduction (Dong et al., 2016; 2014, Rabinal et al., 2013).

However, the chemical reduction of silver ions method to metallic silver in the presence of capping agents was reported to be the most popular method for the synthesis of AgNPs (Biçer and Şişman, 2010). Most of the capping agents or reducing agents used in these chemical methods may induce toxic effect resulting in risks to the environment (Oluwafemi et al., 2013). Moreover, the use of such environmental toxic chemicals may limit the application of AgNPs. Consequently, to minimize these environmental hazardous chemicals and to maximize the safety and efficiency of AgNPs, several approaches were developed to prepare AgNPs using green chemistry (Oluwafemi et al., 2013).

The plant extract is one of the most promising method used as stabilizing and reducing agents. The leaf extract of several plants were used for the synthesis of AGNPs including Gloriosa superba L. (Ashokkumar et al., 2013), Prosopis juliflora (Raja et al., 2012), Rosadamascene (Ghoreishi et al., 2011, Sesbania grandiflora (Das et al., 2013), Rosa rugosa (Dubey et al., 2010), Hibiscus cannabinus (Bindhu et al., 2013), Barbated Skullcup herb (Wang et al., 2009), Anacardium occidentale (Philip and Unni, 2011).

The objectives of the current study were to use mulberry aqueous leaf extract for the green synthesis of AgNPs and to evaluate the antifungal activity and anti-aflatoxin production of both, the plant extract and the synthesized AgNPs.

\section{MATERIALS AND METHODS}

\section{Plant materials}

Ten samples of stored white and yellow grains and fifteen groundnut pods (400 $\mathrm{g}$ each) were collected from 4 different districts at Cairo governorate, Egypt, namely; Gesr ElSuez; Hadeik El-Kobba; El-Zeitoun and El- Haram. Mulberry (Morus nigra, Family: Moraceae) leaves were collected from agricultural areas in Dekernis districts, Mansoura, Egypt during June 2013.

\section{Preparation of plant extract and synthesis of AgNPs}

Twenty-five gram of fresh clean leaves of mulberry were used for preparation of aqueous extract according to Abdel-Aziz et al., (2014). Silver nanoparticles (AgNPs) were synthesized using the mulberry leaf extract as described by Parashar et al., (2009).

\section{Characterization of AgNPs \\ $U V$-vis adsorbance spectroscopy analysis}

The bioreduction of silver nitrate $\left(\mathrm{AgNO}_{3}\right)$ to AgNPs was monitored periodically by UV-vis spectroscopy (Shimazu 2401PC, Mundelein, Il, USA) after the dilution of the samples with deionized water (Raut et al., 2009). The UV-vis spectrometric reading was recorded at a scanning speed of 200 to $800 \mathrm{~nm}$ with water (Leela and Vivekanandan, 2008).

\section{TEM analysis of silver nanoparticles}

The suspension containing AgNPs was sampled by TEM analysis using JEOL model 1200 EX electron microscope (München, Germany). The shape and size of AgNPs were determined from TEM micrographs in reference to Elavazhagan and Arunachalam, (2011).

\section{Isolation and identification of seed borne mycoflora}

Isolation of the seed-borne mycoflora associated with internal seeds of groundnut, yellow and white corn grains was carried out according to the standard agar plate method described by the International Seed Testing Association (ISTA, 2003), on Potato dextrose agar (PDA), Nash and Coon's media. Fungi were macroscopically and microscopically identified on the basis of their typical structure and basic characters as suggested by Melone and Masket, (1964); Barnett and Hunter (1998). Aflatoxigenic isolate of Aspergillus parasiticus was provided by Plant Pathology Department, National Research Center, Giza, Egypt.

\section{In vitro evaluation of the antifungal potency and MIC of mulberry leaf extract and AgNPs against the selected mycoflora}

Aqueous mulberry leaf extract with different concentrations $(0.1,0.2,0.4$ and $0.8 \%)$ was tested for in vitro antifungal potential against the selected fungal pathogens by poisoned food technique and agar well diffusion assay following the modified procedure of Mohana and Raveesha, (2010); Khyade and Vaikos, (2009), respectively. In vitro assay of the antifungal activity of AgNPs was performed on PDA growth medium treated with different concentrations (i.e., 0.1, 0.2, 0.4, $0.8 \%$ and $1.6 \%$ ) of AgNPs using the same above mentioned assays according to Kim et al., (2012); Devi and Bhimba, (2014), respectively. Dithane M45 was used as a positive control antifungal and three replicates of each treatment were performed.

Minimum inhibitory concentrations (MIC) of the extract was determined using poisoned food technique according to Yanar et al., (2011) using various concentrations of the extract $(0.1,0.2$ and $0.4 \%$ ), whereas, MIC of the AgNPs was conducted as described by Hassan et al., (2007) using agar well diffusion method using 0.1 and $0.2 \%$ concentrations only. 


\section{Effect of mulberry leaf extract and AgNPs on mycelial dry weight of selected mycoflora}

The reduction of dry weight of fungal mycelia of the selected mycoflora due to activities of the mulberry extract and AgNPS were conducted as described by Venturini et al., (2002); Agrawal et al., (2004), respectively, using different concentrations mainly $0.1,0.2,0.4,0.8$ and $1.6 \%$.

\section{In vivo estimation of the anti-aflatoxin production activities of the leaf extract and AgNPs}

The in vivo anti-aflatoxin potency of the plant extract and AgNPs on aflatoxin $\mathrm{B}_{1}\left(\mathrm{AFB}_{1}\right)$ production in corn grains infested with the aflatoxigenic $A$. parsiticus was determined following the procedures of Garcia et al., (2012). However, $\mathrm{AFB}_{1}$ extraction and quantification were conducted according to Singh et al., (1991); VICAM (1999); Shukla et al., (2008) using HPLC analysis.

\section{Statistical analysis}

All data were statistically analyzed using the General Linear Model Procedure of the Statistical Analysis System (SAS 1982). The significance of the differences among treatment groups was determined by Waller-Duncan k-ratio (Waller and Duncan, 1969). All statements of significance were based on probability of $\mathrm{P} \leq 0.05$.

\section{RESULTS}

\section{Isolation of mycoflora from stored maize grains and groundnut seeds}

The results of isolation and identification of seed borne mycoflora revealed that 16 different fungal species belonging to 7 genera were obtained mainly: Fusarium verticillioides; $F$. oxysporum; Fusarium spp.; Aspergillus flavus; A. niger; A. terreus; A. parasiticus; A. candidus; A. tamari; A. sydowii; Penicillium carryophylum; Alternaria sp.; Mucor spp.; Gliocladium fimbriatum; Rhizopus stolonifer and Rhizopus sp. Five isolates known of being pathogens and mycotoxins producers mainly; A. flavus; A. terreus; F. oxysporum; F. verticillioides and $P$. carryophylum were selected for further research, whereas, the remaining isolates were neglected.

Results in Table 1 showed that the number of fungal count isolated from white corn samples collected from Gesr ElSuez district using PDA medium was the highest (409 CFU/ 100 seeds) with infection ratio of $90.90 \%$ followed by the samples collected from Hadeik El-Koba which recorded 250 CFU/ 100 seeds with infection ratio of $68.75 \%$.

However, the samples collected from El-Haram recorded TFC of 75 CFU/ 100 seeds with infection ratio of $18.75 \%$ and the samples collected from El-Zeiton recorded $50 \mathrm{CFU/100}$ seeds with infection ratio of $12.5 \%$. The yellow corn samples collected from Hadik El-Koba was found to be the most fungal infected samples and the recorded TFC using PDA medium was $450 \mathrm{CFU/}$
100 seeds followed by the samples collected from Gesr El-Suez which recorded $233 \mathrm{CFU} / 100$ seeds, then those collected from El Zeiton and El-Haram which recorded $150 \mathrm{CFU} / 100$ and $100 \mathrm{CFU} /$ 100 seeds, respectively. The percentage of infection for the 4 districts were $100,75,31.25$ and $6.25 \%$ for the samples collected from Hadik El-Koba, Gesr El-Suez, El-Zeiton and El-Haram, respectively.

Moreover, the recorded TFC in groundnut samples collected from the four districts using PDA were 225, 450, 118 and 113 for Gesr El-Suez, Hadeik El-Koba, El-Zeiton and ElHaram, respectively with percentages of infection reached 81.25, 100,25 and $50 \%$ respectively.

The results presented in Table (1) also revealed that TFC isolated from white corn using Nash medium recorded 362, 106, 69 and 32 CFU/ 100 seeds for Gesr El-Suez, Hadeik ElKoba, El-Zeiton and El-Harm, respectively which were corresponding to $93.75,43.75,18.75$ and $12.5 \%$ for these districts, respectively. Using the same medium, TFC in yellow corn samples collected from the 4 districts recorded 208, 325, 57 and $250 \mathrm{CFU} / 100$ seeds with percentages of infection reached $66.66,75,12.5$ and $62.5 \%$ for the samples collected from Gesr El-Suez, Hadeik El-Koba, El-Zeiton and El-Haram, respectively.

TFC recorded for groundnut samples collected from the four districts using Nash medium were 275, 408 and 25 for the samples collected from Hadik El-Koba, Gesr El-Suez and ElHaram, respectively, however; the groundnut samples collected from El-Zeiton did not record any infection using this medium. However, the TFC recorded for white corn using Coon's medium isolated from the samples collected from Gesr El-Suez, Hadeik ElKoba, El-Zeiton and El-Haram were 368, 62, 75 and 125, respectively with recorded percentages of infection reached $93.75,37.75,18.75$ and $18.75 \%$ for the four districts, respectively.

On the other hand, the TFC recorded in yellow corn collected from the 4 districts using Coon's medium were 377, 441, 144 and $125 \mathrm{CFU} / 100$ seeds for the samples collected from the 4 studied areas, respectively. The recorded infection percentages were $93.75,75,37.5$ and 43.75 for the same districts, respectively. The recorded TFC for groundnuts samples collected from these districts using Coon's medium were 266, 400, 168 and 663 CFU/ 100 seeds with infection ratio reached 100, 93.75, 37.5 and $100 \%$, respectively.

\section{Characterization of AgNPs}

Addition of mulberry leaf extract to silver nitrate $(1 \mathrm{mM})$ in darkness resulted in changing its color to brownish indicating the formation of AgNPs, (Fig. 2a) and the produced solution showed Uv/Vis absorbance at $425 \mathrm{~nm}$ (Fig. 1b). Transmittance electron microscope (TEM) studies approved that the diameter of the nanoparticles ranged from 4 to 8 nm (Fig. 1c). 

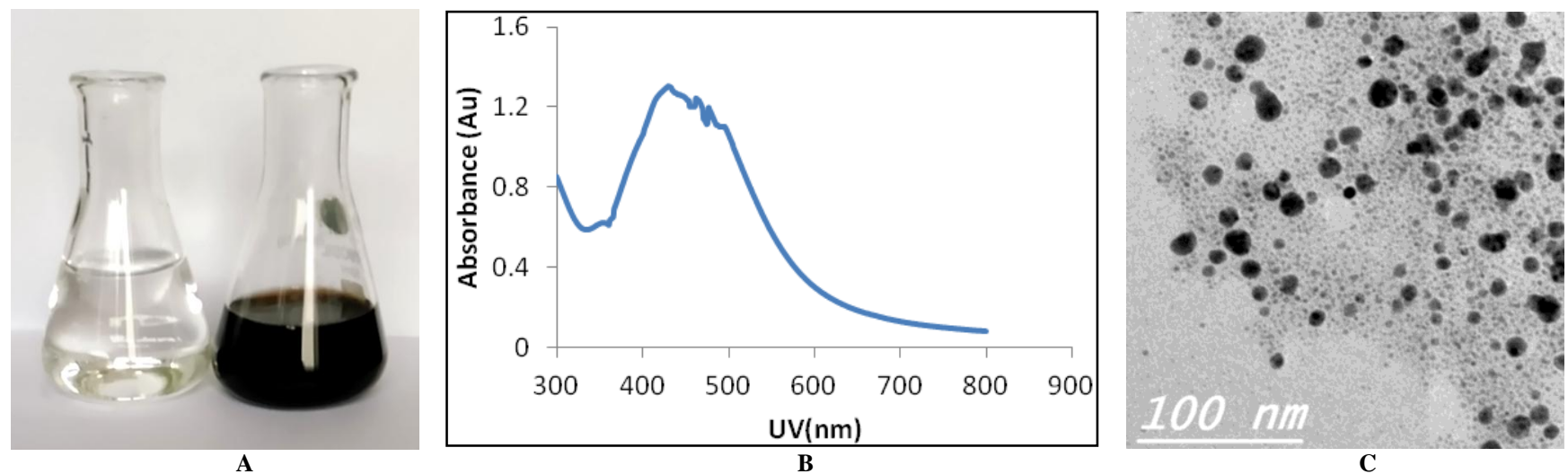

Fig. 1: (a) Color development of silver nitrate to AgNPs (brown) by the addition of mulberry leaf extract; (b) The spectrum of AgNPs synthesized by aqueous leaf extract of mulberry detected through Uv/Vis absorbance and (c) TEM photograph of AgNPs biosynthesized by mulberry leaf extract.

Table 1: Percentage of fungal infection and number of total fungal counts (CFU/100 seeds) associated with white, yellow corn grains and groundnut seeds collected from 4 locations in Cairo on three different media.

\begin{tabular}{|c|c|c|c|c|c|c|c|}
\hline \multirow{2}{*}{ Location } & \multirow{2}{*}{ Media } & \multicolumn{2}{|c|}{ White corn } & \multicolumn{2}{|c|}{ Yellow corn } & \multicolumn{2}{|c|}{ Groundnut } \\
\hline & & Infection \% & CFU/100 & Infection \% & CFU/100 & Infection \% & CFU/100 \\
\hline \multirow{3}{*}{ Gesr El-Suez } & PDA & 90.90 & 409 & 75 & 233 & 81.25 & 225 \\
\hline & Nash & 93.75 & 362 & 66.66 & 208 & 87.5 & 275 \\
\hline & Coon's & 93.75 & 368 & 93.75 & 337 & 100 & 266 \\
\hline \multirow{3}{*}{ Hadeik El-Koba } & PDA & 68.75 & 250 & 100 & 450 & 100 & 450 \\
\hline & Nash & 43.75 & 106 & 75 & 325 & 83.33 & 408 \\
\hline & Coon's & 37.5 & 62 & 75 & 441 & 93.75 & 400 \\
\hline \multirow{3}{*}{ El-Zeiton } & PDA & 12.5 & 50 & 31.25 & 150 & 25 & 118 \\
\hline & Nash & 18.75 & 69 & 12.5 & 57 & 0 & 0 \\
\hline & Coon's & 18.75 & 75 & 37.5 & 144 & 37.5 & 168 \\
\hline \multirow{3}{*}{ El-Haram } & PDA & 18.75 & 75 & 6.25 & 100 & 50 & 113 \\
\hline & Nash & 12.5 & 32 & 62.5 & 250 & 25 & 63 \\
\hline & Coon's & 18.75 & 125 & 43.75 & 125 & 100 & 663 \\
\hline
\end{tabular}

Table 2: Mean diameter of inhibition of radial growth of the tested fungi treated with the plant extract and AgNPs using poisoned food technique.

\begin{tabular}{|c|c|c|c|c|c|c|c|c|c|c|c|}
\hline \multirow[b]{2}{*}{ Fungi } & \multirow[b]{2}{*}{ Control } & \multicolumn{2}{|c|}{ Fungicide } & \multicolumn{4}{|c|}{ Plant extract } & \multicolumn{4}{|c|}{ AgNPs } \\
\hline & & $\begin{array}{l}0.8 \\
\%\end{array}$ & $\begin{array}{l}1.6 \\
\%\end{array}$ & $0.1 \%$ & $0.2 \%$ & $0.4 \%$ & $0.8 \%$ & $0.1 \%$ & $0.2 \%$ & $0.4 \%$ & $0.8 \%$ \\
\hline A. flavus & $84.33 \pm 0.47$ & 0 & 0 & $81.6 \pm 0.24$ & $79.6 \pm 0.24$ & $49.6 \pm 2.01$ & $26.3 \pm 0.63$ & $74.3 \pm 0.63$ & $31.3 \pm 0.47$ & $29.3 \pm 0.24$ & $20.6 \pm 0.24$ \\
\hline A. terreus & $80.0 \pm 0$ & 0 & 0 & $74.0 \pm 0.82$ & $53.6 \pm 0.85$ & $40 \pm 0.41$ & $22.0 \pm 0.41$ & $74.0 \pm 0.82$ & $53.6 \pm 0.85$ & $40.0 \pm 0.41$ & $22.0 \pm 0.41$ \\
\hline F. oxysporum & $90.0 \pm 0$ & 0 & 0 & $64 \pm 1.081$ & $55.0 \pm 1.081$ & $40.0 \pm 0.41$ & $28.0 \pm 0.41$ & $54.3 \pm 0.85$ & $42.3 \pm 0.63$ & $32.0 \pm 0.41$ & $21.3 \pm 0.24$ \\
\hline F. verticillioides & $90 \pm 0$ & 0 & 0 & $64 \pm 1.081$ & $61.6 \pm 0.623$ & $55.3 \pm 1.93$ & $55.3 \pm 0.849$ & $60.0 \pm 0$ & $57.3 \pm 0.235$ & $54.5 \pm 0.250$ & $49.0 \pm 0.41$ \\
\hline P. carryophylum & $80.66 \pm 0.63$ & 0 & 0 & $61.66 \pm 0.24$ & $31.0 \pm 0.41$ & $26.33 \pm 0.63$ & $23.33 \pm 0.63$ & $41.33 \pm 0.63$ & $23.33 \pm 0.24$ & $22.0 \pm 0.41$ & $20.33 \pm 0.24$ \\
\hline
\end{tabular}

Values are averages of three replicates for each treatment \pm SE.

Table 3: Mean diameter of inhibition of radial growth of the tested fungi treated with the plant extract and AgNPs using Agar well diffusion.

\begin{tabular}{|c|c|c|c|c|c|c|c|c|c|c|c|c|}
\hline \multirow[b]{2}{*}{ Fungi } & \multirow[b]{2}{*}{ Control } & \multirow{2}{*}{$\begin{array}{c}\text { Fungicide } \\
1.6 \%\end{array}$} & \multicolumn{5}{|c|}{ Plant extract } & \multicolumn{5}{|c|}{ AgNPs } \\
\hline & & & $\begin{array}{c}0.1 \\
\%\end{array}$ & $\begin{array}{c}0.2 \\
\%\end{array}$ & $0.4 \%$ & $0.8 \%$ & $1.6 \%$ & $\begin{array}{c}0.1 \\
\%\end{array}$ & $0.2 \%$ & $0.4 \%$ & $0.8 \%$ & $1.6 \%$ \\
\hline A. flavus & 0 & $36.0 \pm 0.41$ & 0 & 0 & 0 & $5.66 \pm 0.24$ & $9.33 \pm 0.24$ & 0 & 0 & $6.66 \pm 0.24$ & $8.33 \pm 0.24$ & $11.6 \pm 0.63$ \\
\hline A. terreus & 0 & $33.66 \pm 0.63$ & 0 & 0 & 0 & $10.0 \pm 0.41$ & $7.33 \pm 0.24$ & 0 & 0 & $11.33 \pm 0.63$ & $11.0 \pm 0.41$ & $7.66 \pm 0.24$ \\
\hline F. oxysporum & 0 & $41.66 \pm 0.47$ & 0 & 0 & $8.0 \pm 1.18$ & $13 \pm 0.41$ & $20.3 \pm 0.63$ & 0 & $9.3 \pm 0.47$ & $7.6 \pm 0.24$ & $24.0 \pm 0.41$ & $30.3 \pm 0.47$ \\
\hline F. verticillioides & 0 & $42.33 \pm 0.63$ & 0 & 0 & $7.0 \pm 0.41$ & $16.3 \pm 0.85$ & $20.6 \pm 0.24$ & 0 & $7.6 \pm 0.24$ & $16.0 \pm 0.41$ & $20.6 \pm 0.63$ & $25.6 \pm 0.85$ \\
\hline P. carryophylum & 0 & $41.67 \pm 0.47$ & 0 & 0 & $5.67 \pm 0.24$ & $6.33 \pm 0.24$ & $9.0 \pm 0.41$ & 0 & $8.0 \pm 0.41$ & $11.0 \pm 0.41$ & $12.75 \pm 0.48$ & $18.0 \pm 0.82$ \\
\hline
\end{tabular}

Values are averages of three replicates for each treatment \pm SE.

\section{In vitro antifungal potential of the mulberry extract and AgNPs on the selected mycoflora}

The current results demonstrated that the antifungal potency of the plant extract and AgNPs against the selected fungi was increased with increasing their corresponding concentrations. In poisoned food technique (Table 2), the mean diameter of radial growth of all tested fungi was decreased significantly in a dose dependent manner after the addition of the plant extract or AgNPs.
However, synthetic fungicide caused complete inhibition of the growth of all fungal species at concentration of $0.8 \%$ and $16 \%$. Moreover, these results showed that AgNPs was more effective than the plant extract. In agar well diffusion assay (Table 3 ), the inhibitory activities of the AgNPs against the radial growth of $P$. Carryophylum was almost double that of the plant extract at all tested concentrations. However, AgNPs could inhibit the radial growth of the other tested fungi in a dose dependent fashion. 
Determination of the minimum inhibitory concentrations (MIC) of plant extract and AgNPs against seed borne fungi

The minimum inhibitory concentrations (MIC) of the plant extract and AgNPs causing MIC are shown in Table (4). In poisoned food technique, the MIC of plant extract and AgNPs against the five selected seed borne fungi was $0.1 \%$. This low concentration demonstrates the high antifungal activities of plant extract and the AgNPs.

Table 4: Minimum inhibitory concentrations (MIC) of plant extract and AgNPs against seed borne fungi using poisoned food and agar well diffusion techniques.

\begin{tabular}{lcccc}
\hline \multirow{3}{*}{ Seed borne mycoflora } & \multicolumn{3}{c}{ Minimum Inhibitory Conc. (MIC) } \\
\cline { 2 - 5 } & \multicolumn{2}{c}{$\begin{array}{c}\text { Poisoned food } \\
\text { technique }\end{array}$} & $\begin{array}{c}\text { Agar well diffusion } \\
\text { technique }\end{array}$ \\
\cline { 2 - 5 } & $\begin{array}{c}\text { Plant } \\
\text { extract }\end{array}$ & AgNPs & $\begin{array}{c}\text { Plant } \\
\text { Extract }\end{array}$ & AgNPs \\
\hline A. flavus & $0.10 \%$ & $0.10 \%$ & $0.80 \%$ & $0.40 \%$ \\
A. terreus & $0.10 \%$ & $0.10 \%$ & $0.80 \%$ & $0.40 \%$ \\
F. verticillioides & $0.10 \%$ & $0.10 \%$ & $0.40 \%$ & $0.20 \%$ \\
F. oxysporum & $0.10 \%$ & $0.10 \%$ & $0.40 \%$ & $0.20 \%$ \\
P. carryophylum & $0.10 \%$ & $0.10 \%$ & $0.40 \%$ & $0.20 \%$ \\
\hline
\end{tabular}

In case of agar well diffusion technique, the MIC of the plant extract against $F$. verticillioides, $F$. oxysporum and $P$. carryophylum was $0.4 \%$, whereas, it was $0.8 \%$ against A. flavus, A. terreus which revealed that the high concentrations

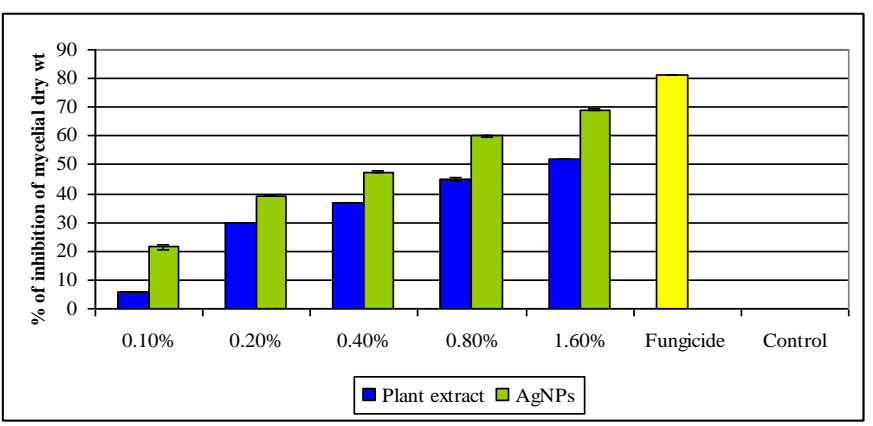

A. flavus

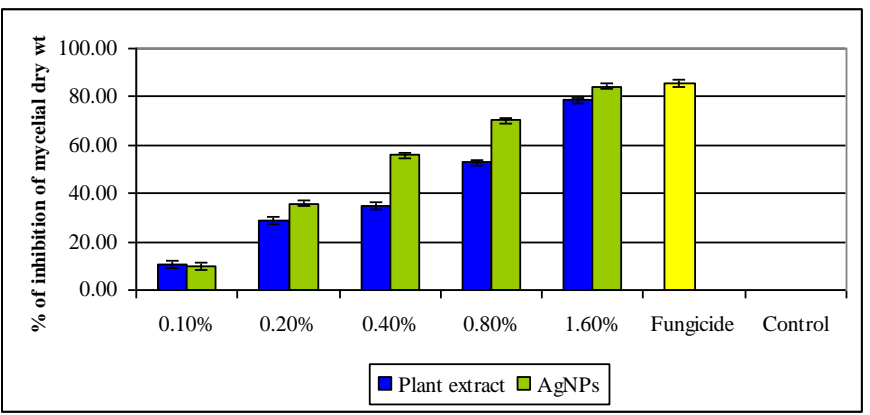

F. verticillioides

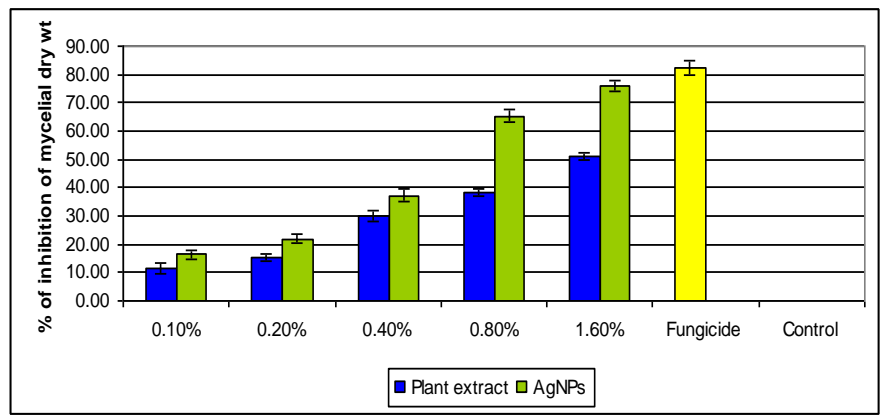

P. carryophylum demonstrating the low activity of the plant extract in this used technique. On the other hand, the MIC of AgNPs was $0.2 \%$ against $F$. verticillioides, $F$. oxysporum and $P$. carryophylum, and $0.4 \%$ against $A$. flavus, $A$. terreus.

These results demonstrated the higher activity of AgNPs against seed borne fungi compared with the plant extract, higher resistance of $A$. flavus and $A$. terreus to both agents, on the contrary to $F$. verticillioides, $F$. oxysporum and $P$. carryophylum which showed more sensitivity. In addition, these results demonstrated also that the poisoned food technique was more sensitive and accurate than the agar well diffusion technique.

\section{Effect of the mulberry extract and AgNPs on mycelial dry weight of the selected mycoflora}

The inhibitory effects of the plant extract and AgNPs on the mycelial dry weight of the tested fungi (Fig. 2) revealed that the inhibition of mycelia dry weight was increased with increasing their corresponding concentrations. The synthetic fungicide caused higher inhibition percentage $(82.20 \%)$, compared with the same concentration of both agents. This inhibition of myceial dry weigh was more pronounced with AgNPs for A. flavus, A. terreus and $P$. carryophylum at all tested concentrations tested. However, the plant extract at $0.1 \%$ showed an insignificant increase in mycelia dry weight for $F$. verticillioides and $F$. oxysporum.

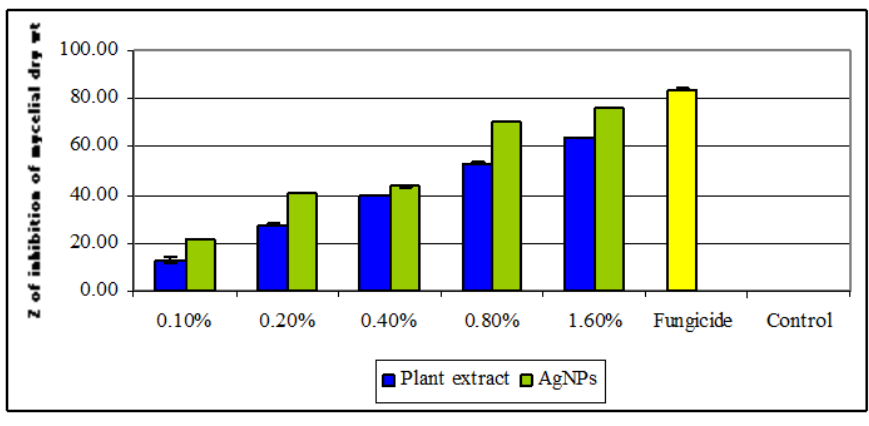

A. terreus

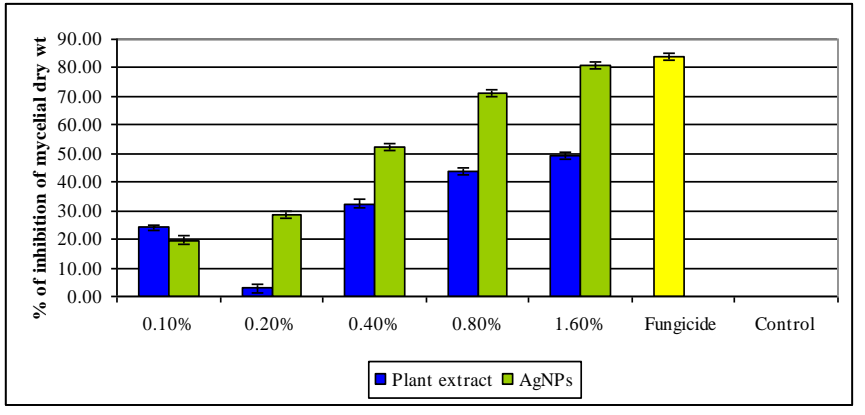

F. oxysporum

Fig. 2: Effect of plant extract and AgNPs on mycelial dry wt. of the tested fungi. 


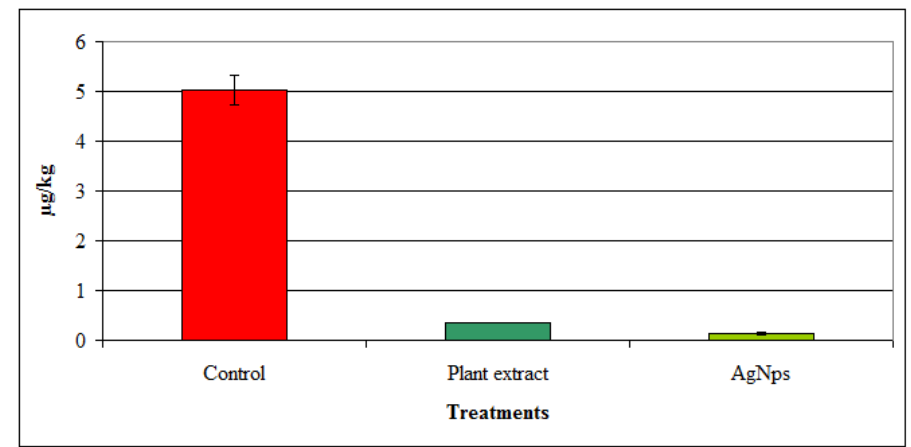

Fig. 3: Total aflatoxin concentration in non-treated corn grains and grains treated with the plant extract or AgNPs.

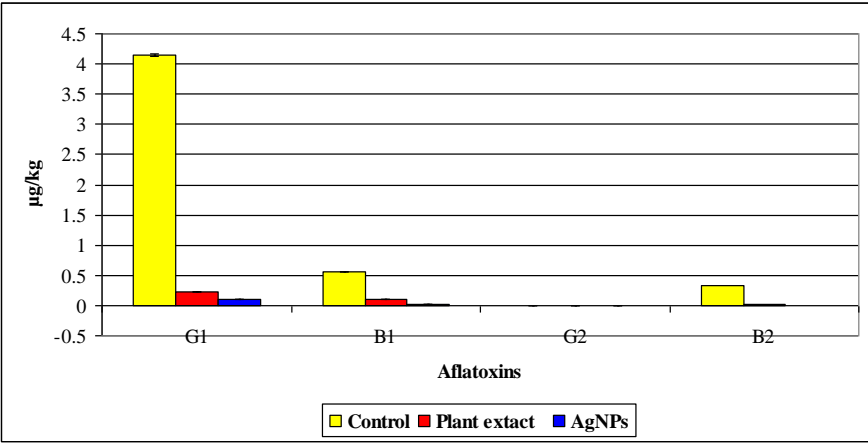

Fig. 4: Concentration of aflatoxins in corn grains infested with A. parsiticus only and those treated with the plant extract or AgNPs

\section{Anti-aflatoxin production in corn grains treated with the plant extract and AgNPs}

The HPLC analysis of aflatoxin in the infested corn grains revealed the presence of total aflatoxins in a concentration reached $5.03 \mu \mathrm{g} / \mathrm{kg}$ corn grain sample, however, the concentration of total aflatoxin in the infested corn grain treated with the plant extract or AgNPs reached 0.35 and $0.13 \mu \mathrm{g} / \mathrm{kg}$, respectively (Fig. 3). Moreover; the data revealed the absence of $\mathrm{AFG}_{2}$ in all treated and untreated samples, whereas, $\mathrm{AFB}_{2}$ was only absent in the samples treated with AgNPs (Fig. 4).

\section{DISCUSSION}

In the current study, the isolation and identification of seed borne mycoflora showed that 16 different fungal species belonging to 7 genera were obtained mainly: Fusarium, Aspergillus, Penicillium, Alternaria, Mucor, Gliocladium and Rhizopus. The results also revealed that all the yellow and white corn grains and peanuts seeds collected from different districts in Cairo are infected with these fungal species which may be due to the bad storage conditions. Similar to the current results, Madbouly et al., (2012) reported that 23 species belonging to 12 different genera of fungi were isolated from corn grains collected from different districts of Cairo governorate, the percentages of infection of corn ranged from $16 \%$ to $142 \%$. About $70 \%$ of these samples were infected with Aspergillus flavus and Aspergillus niger with percentages of $33 \%, 40 \%$, respectively.

Biological synthesis of AgNPs using plant extracts is safe and has no phytotoxic effects (Gardea-Torresdey et al., 2003). Aqueous silver ions were reduced to AgNPs after mixing with mulberry leaves and change in color to reddish brown has been previously observed (Khandelwal et al., 2010) which was suggested to be due to the surface plasmon resonance of deposited AgNPs. Following the TEM study, the size of the nanoparticles ranged approximately from 4 to $8 \mathrm{~nm}$, which are in the size range to impart higher antimicrobial effect (Khadri et al., 2013).

The antifungal potency of the plant extract and AgNPs were examined against the five selected seed-borne fungi, using poisoned food and agar well diffusion techniques.
In all treatments, AgNPs exhibited higher antifungal activity even at low concentration $(0.1 \%)$, this could be attributed to the stability of the synthesized AgNPs. The antifungal potency of the plant extract and AgNPs increased with increasing their corresponding concentrations. However the sensitivity to this extract varied with different isolates which may be due to the difference in intrinsic tolerance of these isolates, in addition to the nature and combinations of phytocompounds present in this crude extract (Senguttuvan et al., 2013). In accordance, Radojković et al., (2012) stated that mulberry root extract had high total phenolics contents (186.30 $\mathrm{mg} \mathrm{CAE} / \mathrm{g})$, whereas, high total flavonoids content $(67.37 \mathrm{mg} \mathrm{RE} / \mathrm{g})$ were determined for its leaf extracts. Whether these phenolic principles acted singly or synergistically, they might prevent and/ or decrease the growth of these fungi by disturbing their respiratory chains, denaturating enzymes and proteins within the fungal cells and might inhibit the biosynthetic pathways of mycotoxins in these fungi (Madbouly and El Magly, 2015). In poisoned food technique, $P$. carryophylum was highly sensitive to AgNPs and mulberry extract followed by $A$. flavus, conversely; $F$. verticilliodes was resistant to both agents as it recorded the highest diameter of radial growth. In agar well diffusion assay, A. flavus and A. terreus were sensitive only to high concentrations of the plant extract; however, they were resistant to its lower concentrations. The same with Aspergilli were also resistant to low concentrations of the AgNPs. On the other hand, at high concentration of both agents, A. flavus, A. terreus and $P$. carryophylum showed the least diameters of inhibition zones, indicating the higher resistance of these fungi to both control agents. Similar results were observed with A. flavus; A. terreus; $F$. oxysporum and $F$. verticillioides. On using the poisoned food technique, the MIC of the plant extract and AgNPs was very low about $0.1 \%$, indicating the effectiveness of both agents against all selected seed-borne fungi. Meanwhile, in case of the agar well diffusion assay, the MIC of AgNPs against $F$. verticilliodes, $F$. oxysporum and $P$. carryophylum was $0.2 \%$, however, it was $0.4 \%$ against $A$. flavus and A. terreus, therefore low concentrations of silver nanoparticles could inhibit growth of these mycoflora. Both agents caused considerable inhibition in the mycelial dry weight. of all selected fungi. F. verticilliodes showed 
maximum sensitivity to the plant extract and AgNPs. Conversely, F. oxysporum showed maximum resistance to the plant extract (49.1\%), whereas, A. flavus recorded high resistance to the AgNPs. These activities of both agents could be attributed to the denaturation of proteins and consequently inhibiting the action of enzyme systems responsible for growth of these fungi. This recorded high antifungal potency of the AgNPs might be because upon treatment with $\mathrm{Ag}^{+}$, the DNA loses its ability to replicate (Feng et al., 2000), Leading to inactivated expression of ribosomal subunit proteins, as well as certain other cellular proteins and enzymes essential to ATP production (Yamanaka et al., 2005), hence inhibiting the biosynthetic pathways of aflatoxins in $A$. parasiticus isolate. Generally, nanopesticides represent the nextgeneration to traditional pesticides, as they have higher efficacy, durability and less doses of active ingredients (Khot et al., 2012). For the best of our knowledge, the current study is the first report of using mulberry leaf extract for the green synthesis of AgNPs.

Aflatoxins (AFs) are secondary metabolites with toxic and carcinogenic effects, produced by species of Aspergillus, particularly A. flavus and A. parasiticus (Razzaghi-Abyaneh et al., 2008). In the current study, the HPLC analysis of total aflatoxins present in corn grains co-inoculated separately with the plant extract, AgNPs and the aflatoxigenic isolate of $A$. parasiticus showed reduction of its level to 0.35 and $0.13 \mu \mathrm{g} / \mathrm{kg}$, respectively, compared with $5.03 \mu \mathrm{g} / \mathrm{kg}$ in corn grains infested with the aflatoxigenic isolate only.

\section{CONCLUSION}

It could be concluded from the results of the current study that AgNPs could be green synthesized by mulberry leaf extract and then used effectively as safe, ecofriendly nanofungicides to inhibit the fungal growth and subsequent aflatoxins production in cereal grains during storage.

\section{ACKNOWLEDGMENTS}

Financial support and sponsorship: This work was supported by the National Research Centre, Dokki, Cairo, Egypt, project \# 10070112 and the Faculty of Science, Ain-Shams University.

Conflict of Interests: There are no conflicts of interest.

\section{REFERENCES}

Abdel-Aziz MS, Shaheen MS, El-Nekeety AA, Abdel-Wahhab MA. Antioxidant and antibacterial activity of silver nanoparticles biosynthesized using Chenopodium murale leaf extract. J Saudi Chem Soc, 2014; 18: 356-363.

Agrawal A, Srivastava S, Srivastava JN, Srivasava, MM. Evaluation of inhibitory effect of the plant Phyllanthus amarus against dermatophytic fungi Microsporum gypseum. Biomed Environ Sci, 2004; 17: 359-365

Ashokkumar S, Ravi S, Velmurugan S. Green synthesis of silver nanoparticles from Gloriosa superba L. leaf extract and their catalytic activity. Spectrochim Acta A, 2013; 115: 388-392.

Barnett HL, Hunter BB. The Illustrated Genera of Imperfect Fungi. $4^{\text {th }}$ Edition Aps Press, The American Phytopathological society, St. Paul, Minnesota. 1998; P. 218.
Bhat R, Reddy KR. Challenges and issues concerning mycotoxins contamination in oil seeds and their edible oils: Updates from last decade. Food Chem, 2017; 215: 425-437.

Biçer M, Şişman I. Controlled synthesis of copper nano/microstructures using ascorbic acid in aqueous CTAB solution. Powder Technol, 2010; 198: 279-284.

Bindhu MR, Umadevi M. Synthesis of monodispersed silver nanoparticles using Hibiscus cannabinus leaf extract and its antimicrobial activity. Spectrochim Acta A, 2013; 101: 184-190.

Bryden WL. Mycotoxin contamination of the feed supply chain: Implications for animal productivity and feed security. Animal Feed Sci Technol, 2012; 173: 134-158.

CAST. Mycotoxins: Risks in Plant, Animal, and Human Systems. Task Force Report, 2003; No. 139. Ames, IA

Das J, Paul M, Das P. Sesbania grandiflora leaf extract mediated green synthesis of antibacterial silver nanoparticles against selected human pathogens. Spectrochim Acta A, 2013; 104: 265-270.

Devi JS, Bhimba BV. Antibacterial and antifungal activity of silver nanoparticles synthesized using Hypnea muciformis. Biosci Biotechnol Res ASIA, 2014;11(1): 235-238.

Dong C, Zhang X, Cai H, Cao C. Sodium alginate mediated route for the synthesis of monodisperse silver nanoparticles using glucose as reducing agents. Rare Metal Mater Eng, 2016; 45: 261-266.

Dong C, Zhang X, Cai H. Green synthesis of monodisperse silver nanoparticles using hydroxy propyl methyl cellulose. J Alloys Compounds, 2014; 583: 267-271.

Dubey SP, Lahtinen M, Sillanpää M. Green synthesis and characterizations of silver and gold nanoparticles using leaf extract of Rosa rugosa. Colloids Surface A, 2010; 364: 34-41.

Elavazhagan T, Arunachalam KD. Memecylon edule leaf extract mediated green synthesis of silver and gold nanoparticles. Int J Nanomed, 2011; 6: 1265-1278.

Feng QL, Wu J, Chen GQ, Cui FZ, Kim, TN, Kim JO. A mechanistic study of the antibacterial effect of silver ions on Escherichia coli and Staphylococcus aureus. J Biomed Mater Res, 2000; 52: 662-8.

Garcia D, Ramos AJ, Sanchis V, Marin S. Effect of Equisetum arvense and Stevia rebaudiana extracts on growth and mycotoxin production by Aspergillus flavus and Fusarium verticillioides in maize seeds as affected by water activity. Int J Food Microbiol, 2012; 153: 21 27.

Gardea-Torresdey JL, Gómez E, Peralta-Videa JR, Parsons JG, Troiani H, Jose-Yacaman, M. Alfalfa sprouts: a natural source for the synthesis of silver nanoparticles. Langmuir, 2003; 19(4): 1357-1361.

Ghoreishi SM, Behpour M, Khayatkashani M. Green synthesis of silver and gold nanoparticles using Rosa damascena and its primary application in electrochemistry. Physica E, 2011; 44: 97-104.

Gisi U. Assessment of selection and resistance risk for demethylation inhibitor fungicides in Aspergillus fumigatus in agriculture and medicine: a critical review. Pest Manag Sci, 2014; 70(3): 352-364.

Hassan SW, Lawal M, Muhammad BY, Umar RA, Bilbis LS, Faruk UZ, Ebbo AA. Antifungal activity and phytochemical analysis of column chromatographic fractions of stem bark extracts of Ficus sycomorus L. (Moraceae). J Plant Sci, 2007; 2: 209-215.

ISTA. 2003. International Seed Testing Association.

Khadri H, Alzohairy M, Janardhan A, Kumar AP, Narasimha G. Green synthesis of silver nanoparticles with high fungicidal activity from olive seed extract. Adv Nanopart, 2013; 2: 241-246.

Khyade MS, Vaikos NP. Phytochemical and antibacterial properties of leaves of Alstonia scholaris R. Br. Afr biotechnol, 2009; 8: 6434-6436.

Khandelwal N, Singh A, Jain D, Upadhyay MK, Verma HN. Green synthesis of silver nanoparticles using Argimone maxicana leaf extract and evaluation of their activity. Digest J Nanomat Biostr, 2010; 5: 483-489.

Khot LR, Sankaran, S, Maja, JM, Ehsani, R, Schuster EW. Applications of nanomaterials in agricultural production and crop protection: A review. Crop Prot, 2012; 35: 64-70. 
Kim SW, Jung, JH, Lamsal K, Kim YS, Min JS, Lee YS. Antifungal effects of Silver Nanoparticles (AgNPs) against Various Plant Pathogenic Fungi. Mycobiol, 201240; 53-58.

Leela A, Vivekanandan, M. Tapping the unexploited plant resources for the synthesis of silver nanoparticles. Afr J Biotechnol, 2008; 7: 3162-3165.

Li Y, Gan W, Zhou J, Lu Z, Yang C, Ge T. Hydrothermal synthesis of silver nanoparticles in Arabic gum aqueous solutions. T Nonferr Metal Soci, 2015 25; 2081-2086.

Madbouly AK, El-Magly UE. Efficacy of extracts of some plants in avoiding fungal diseases of stored cereals. Int J Pharm Sci, 2015; (7): 441-448.

Madbouly AK, Ibrahim MIM, Sehab AF, Abdel-Wahhab MA. Co-occurrence of mycoflora, aflatoxins and fumonisins in maize and rice seeds from markets of different districts in Cairo, Egypt. Food Add Contam, 2012; 5(2): 112-120.

Melone JP, Maskett AE. Seed-borne fungi. Proc. Int Seed Testing Assoc, 1964; 29: 179-384.

Mohana DC, Raveesha KA. Antimycotic, antibiodeteriorative and antiaflatoxigenic potency of 2-hydroxy-4-methoxybenzaldehyde isolated from Decalepis hamiltonii on fungi causing biodeterioration of maize and sorghum grains. J Mycol Plant Pathol, 2010; 40(2): 197-206.

Naowaratwattana W, De-Eknamkul W, De Mejia EG. Phenoliccontaining organic extracts of mulberry (Morus alba L.) leaves inhibit HepG2 hepatoma cells through G2/M phase arrest, induction of apoptosis, and inhibition of topoisomerase II $\alpha$ activity. J Med Food, 2010; 13: 1045 1056.

Nemanashi M, Meijboom R. Synthesis and characterization of $\mathrm{Cu}, \mathrm{Ag}$ and $\mathrm{Au}$ dendrimer-encapsulated nanoparticles and their application in the reduction of 4-nitrophenol to 4-aminophenol. J Colloid Interface Sci, 2013; 389: 260-267.

Okigbo RN. A review of biological control methods for post harvest yams (Dioscorea spp.) in storage in south eastern Nigeria. KMITL Sci Technol J, 2004; 4(1): 207-215.

Oluwafemi OS, Lucwaba Y, Gura A, Masabeya M, Ncapayi V, Olujimi OO, Songca SP. A facile completely 'green' size tunable synthesis of maltose-reduced silver nanoparticles without the use of any accelerator. Colloids Surface B, 2013; 102: 718-723.

Parashar V, Parashara R, Sharmab B. Parthenium leaf extract mediated synthesis of silver nanoparticles: a novel approach towards weed utilization. Digest J Nanomater Biostr, 2009; 4(1): 45-50.

Philip D, Unni C. Extracellular biosynthesis of gold and silver nanoparticles using Krishna tulsi (Ocimum sanctum) leaf. Physica E, 2011; 43: 1318-1322.

Rabinal MK, Kalasad MN, Praveenkumar K, Bharadi VR, Bhikshavartimath AM. Electrochemical synthesis and optical properties of organicallycapped silver nanoparticles. J Alloy Compd, 2013; 562: 43-47.

Radojković M, Zeković, Z, Mašković, P, Vidović S, Mandić A, Mišan A, Đurović S. Biological activities and chemical composition of Morus leaves extracts obtained by maceration and supercritical fluid extraction. J Supercrit Fluid,. 2016; 117: 50-58.

Radojković MM, Zeković ZP, Vidović SS, Kočar DD, Mašković PZ. Free radical scavenging activity and total phenolic and flavonoid contents of mulberry (Morus spp. L., Moraceae) extracts. Hemijska Industrija, 2012; 66 (4): 547-552.

Raja K, Saravanakumar A, Vijayakumar R. Efficient synthesis of silver nanoparticles from Prosopis juliflora leaf extract and its antimicrobial activityusing sewage. Spectrochim Acta A, 2012; 97: 490494.

Raut RW, Kolekar NS, Lakkakula JR, Mendhulkar VD, Kashid SB. Photosynthesis of silver nanoparticles using Gliricidia sepium (Jecq.). Curr Nanosci, 2009; 5: 117-122.
Razzaghi-Abyaneh M, Ghahfarokhi MS ,Yoshinari T, Rezaee MB, Jaimand K, Nagasawa H, Sakuda S. Inhibitory effects of Satureja hortensis L. essential oil on growth and aflatoxin production by Aspergillus parasiticus. Int J Food Microbiol, 2008; 123: 228-33.

SAS . Statistical analysis system, SAS Institute, 1982; Cary

NC.

Senguttuvan J, Paulsamy S, Krishnamoorthy K. In vitro antifungal activity of leaf and root extracts of the medicinal plant, Hypochaeris radicata L. Int J Pharm Sci, 2013; 5(3): 758-761.

Shukla R, Kumar, A, Prasad, C.S, Srivastava, B, Dubey NK. Antimycotic and antiaflatoxigenic potency of Adenocalymma alliaceum Miers on fungi causing biodeterioration of food commodities and raw herbal drugs. Int Biodete Biodeg, 2008; 62: 348-351.

Singh K, Frisvad JC, Thrane U, Mathur SB. An illustrated manual on identification of some seed-borne Aspergilli, Fusaria, Penicillia and their mycotoxins. $1^{\text {st }}$ Edition, Danish Government Institute of Seed Pathology for Developing Countries, Hellerup, Denmark, 1991; pp.124127.

Stoev SD. Food safety and increasing hazard of mycotoxin occurrence in foods and feeds. Crit Revi Food Sci Nutr, 2013; 53: 887 901.

Venturini ME, Blanco, D, Oria R. In vitro antifungal activity of several antimicrobial compound against Penicillium expansum. J Food prot, 2002; 65(5): 834-839.

VICAM . Aflatest Instruction Manual. Watertown, 1999; MA,

USA.

Waller RA, Duncan DB. Bayes rule for the symmetric multiple comparisons problem. J Am Stat Asso, 1969; 64: 1484-1503.

Wang YHe, X, Wang K, Zhang X, Tan W. Barbated Skullcup herb extract-mediated biosynthesis of gold nanoparticles and its primary application in electrochemistry. Colloid Surface B, 2009; 73: 75-79.

Weber RB, Hrynczuk B, Hrynczuk R, Kita B. Influence of the mode of tillage on diseases of culm base in some winter wheat varieties, oats, and spring wheat. J Phytopathol, 2001; 149: 185-188.

Xu G, Qiao X, Qiu X, Chen J. Green synthesis of highly pure nano-silver sols-electrolysis. Rare Met Mat Eng, 2013; 42: 249-253.

Yamanaka M, Hara K, Kudo J. Bactericidal actions of a silver ion solution on Escherichia coli, studied by energy filtering transmission electron microscopy and proteomic analysis. Appl Environ Microbiol, 2005; 71: 7589-93.

Yanar Y, Gokce A, Kadioglu I, Cam H, Whalon M. In vitro antifungal evaluation of various plant extracts against early blight disease (Alternaria solani) of potato. Afr J Biotechnol, 2011; 10: 8291-8295.

Yan Y, Chen K, Li H, Hong W, Hu X, Xu Z. Capping effect of reducing agents and surfactants in synthesizing silver nanoplates. $\mathrm{T}$ Nonferr Metal Soc, 2014;24: 3732-3738

\section{How to cite this article:}

Hafez RA, Abdel-Wahhab MA, Sehab AF, Karam El-Din AA. Green synthesis of silver nanoparticles using Morus nigra leave extract and evaluation their antifungal potency on phytopathogenic fungi. J App Pharm Sci, 2017; 7 (02): 041-048. 